\title{
Cryo-Electron Microscopy of Latex-Pigment Composites for Enhanced Hiding in Latex Paints.
}

John R Reffner ${ }^{1}$, James Bohling ${ }^{2}$, and Melinda Keefe ${ }^{2}$

1. Analytical Sciences, Dow Chemical Company, Collegeville, PA, USA

2. Dow Coating Materials, Dow Chemical Company, Collegeville, PA, USA

The Dow Chemical Company has developed a new and unique technology, EVOQUE ${ }^{\text {TM }}$ Pre-Composite Polymer, that offers improvements in $\mathrm{TiO}_{2}$ hiding efficiency through the development of a polymer-pigment composite. During the paint making process, the pre-composite polymer combines with $\mathrm{TiO}_{2}$ to form a polymer-pigment composite which improves both the wet and dry hiding efficiency through improved ordering of the $\mathrm{TiO}_{2}$ particles. Because the latex typically used in paints are soft, film forming polymers at room temperatures, Cryo-SEM is useful in characterizing the morphology in the undeformed wet state. Cryo-SEM has been used to characterize various aspects of latex paints including Freeze Thaw behavior[1] $\mathrm{TiO}_{2}$ distribution[2] and $\mathrm{TiO}_{2}$ hiding efficiency[3]. In this work we have used Cryo-SEM to characterize the formation of latex/ $\mathrm{TiO}_{2}$ composites and characterize the resulting film morphology

Equipment: Samples were examined on a JEOL 6700 FESEM using a Gatan Alto 2500 Cryo-SEM Transfer System which includes a preparation chamber mounted directly to the microscope and cryo-stage mounted inside the microscopes chamber.

Characterization of Individual Composite Particles: Key to this technology is the formation of latex- $\mathrm{TiO}_{2}$ composite particles where individual $\mathrm{TiO}_{2}$ particles are encapsulated by a number of latex particles. In order to demonstrate adsorption of the latex onto the $\mathrm{TiO}_{2}$, individual dispersed composite particles were examined. These were prepared by diluting to $0.01 \%$ solids, and nebulizing onto a Cryo-SEM holder cooled with liquid Nitrogen. The SEM holder was then transferred into the Cryo-Preparation Chamber held at $-80^{\circ} \mathrm{C}$ for 20 minutes. This allows the water to sublime, leaving the sample dispersed on the holder. A Chromium coating was applied and the sample was transferred into the SEM and maintained at $-80^{\circ} \mathrm{C}$. Figure 1 shows an example of a composite. The relative reactivity of different $\mathrm{TiO}_{2}$ grades with latex particles can be studied this way. Figure 2 is an example demonstrating the relative adsorption as a function of latex and $\mathrm{TiO} 2$ reactivity. The composite on the left, with higher adsorption, has enhanced hiding (opacity) when formulated into a paint while the unreactive latex has the least hiding.

Characterization of Bulk Films: Top surfaces of films and internal structures were examined by plunge freezing small samples of paint into liquid Ethane. The samples were transferred under liquid nitrogen into the Alto 2500 which was held at $-80^{\circ} \mathrm{C}$. The samples were fractured open using a scalpel and held at $-80^{\circ} \mathrm{C}$ for at least 20 minutes prior to coating with Chromium. Samples were transferred into the SEM and examined at $-80^{\circ} \mathrm{C}$. Figure 3 shows an example of a top surface of a conventional paint and a paint containing composite particles. In the conventional paint the $\mathrm{TiO}_{2}$ particles are present directly on the surface, whereas they are buried beneath at least one layer of latex particles in the case of the composites. The $\mathrm{TiO}_{2}$ particles are also more uniformly distributed in the composite sample. Figure 4 shows an interior of a latex composite sample showing that the composite particles are present in the bulk of the paint. The upper image is collected using a Backscatter detector in Composition mode and 
shows the sub-surface $\mathrm{TiO}_{2}$ particles underneath the latex particles which can be clearly seen in the lower image, collected with a Secondary Electron Detector.

[1] Mittal, M; Roper, JA; Jackson, CL; Monaghan, GG; Francis, LF, JOURNAL OF COLLOID AND INTERFACE SCIENCE 392 (2013) p. 183-193

[2] Wildeson, J; Smith, A; Gong, XB; Davis, HT ; Scriven, LE , JCT COATINGSTECH, 5(7) (2008), p. 32-39

[3] Tiarks, F; Frechen, T; Kirsch, S; Leuninger, J; Melan, M; Pfau, A; Richter, F; Schuler, B; Zhao, CL, PROGRESS IN ORGANIC COATINGS, 48(2-4) (2003) p. 140-152

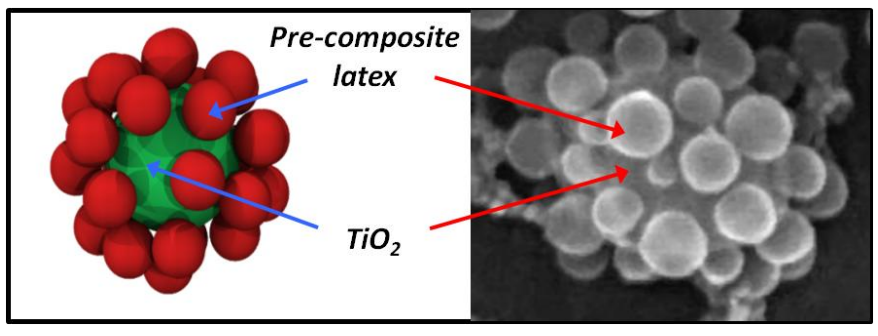

Figure 1. Schematic representation (left) and Cryo-SEM image of a latex- $\mathrm{TiO}_{2}$ composite particle.

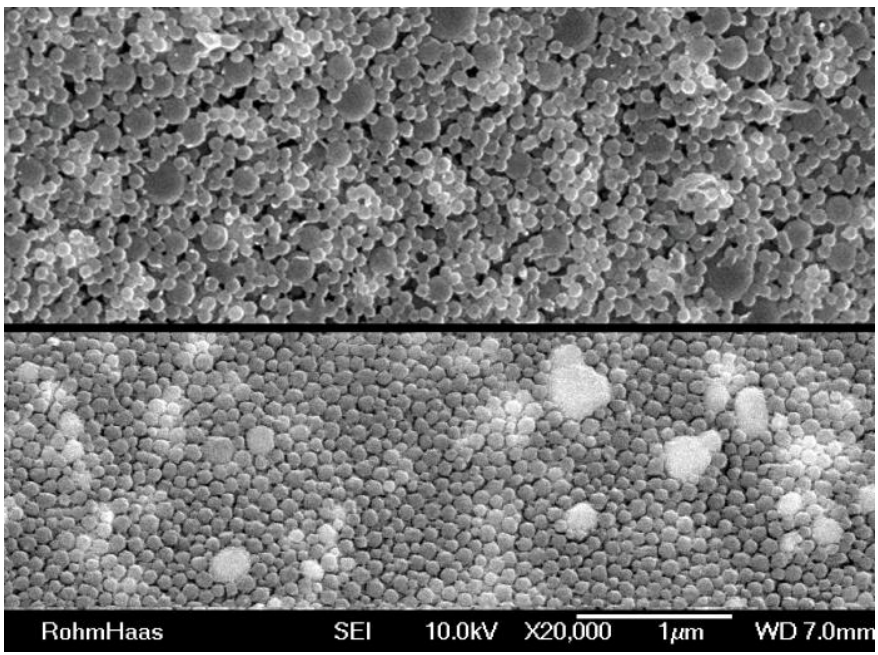

Figure 3. Top surface of paints by Cryo-SEM. Top: Paint formulated with composite particles. Bottom: Paint formulated with conventional latex $/ \mathrm{TiO}_{2}$.

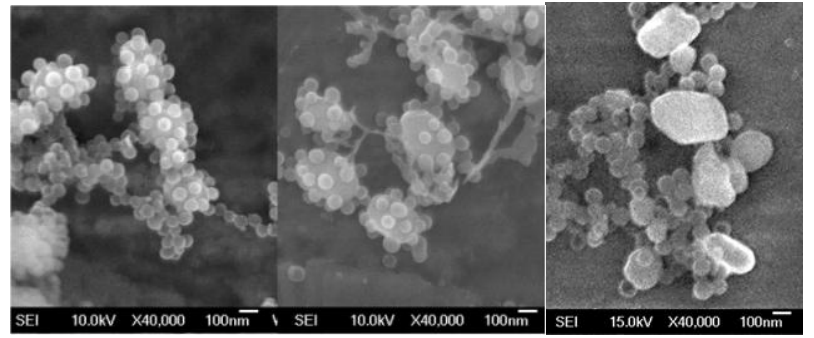

Figure 2. Examples of Latex/ $\mathrm{TiO}_{2}$ Composites. Left: Reactive latex on Kronos 4311. Middle: Reactive Latex on Dupont TiPure R-746. Right: Non-adsorptive latex on Kronos 4311.

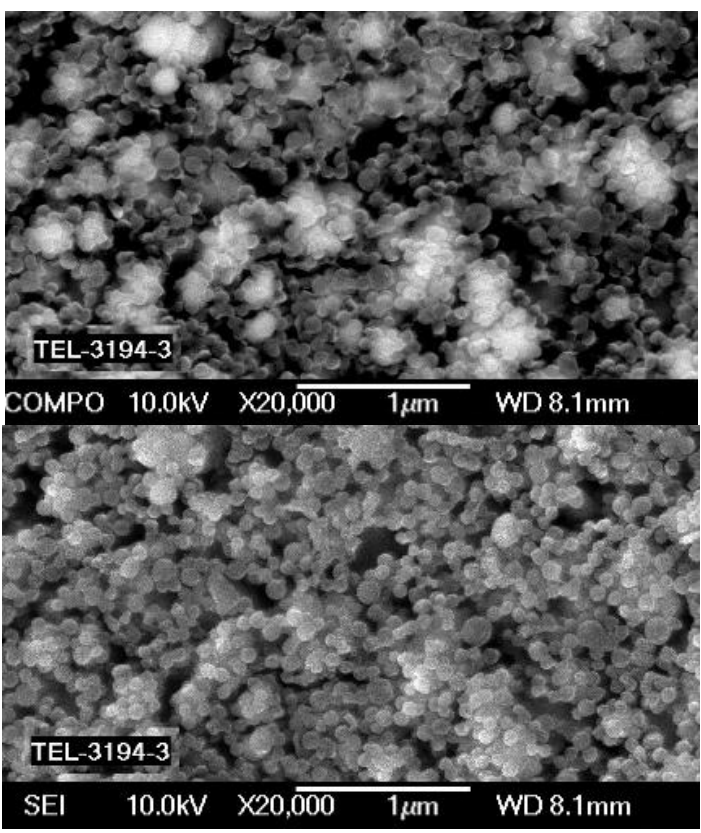

Figure 4. BSI (Composition Mode) and SEI Cryo-SEM images of interior of paint formulated with Latex $/ \mathrm{TiO}_{2}$ composites.

( ${ }^{\text {TM }}$ Trademark of The Dow Chemical Company (“Dow") or an affiliated company of Dow 